\title{
Determination and evaluation of minimum miscibility pressure using various methods: experimental, visual observation, and simulation
}

\author{
Muslim Abdurrahman ${ }^{1, *}$, Wisup Bae ${ }^{2}$, and Asep Kurnia Permadi ${ }^{3}$ \\ ${ }^{1}$ Department of Petroleum Engineering, Universitas Islam Riau, Indonesia \\ ${ }^{2}$ Department of Energy and Mineral Resources Engineering, Sejong University, Republic of Korea \\ ${ }^{3}$ Department of Petroleum Engineering, Institut Teknologi Bandung, Indonesia
}

Received: 8 October 2018 / Accepted: 18 April 2019

\begin{abstract}
This research proposes a simultaneous technique using various methods to yield the most reliable Minimum Miscibility Pressure (MMP) value. Several methods have been utilized in this study including slim tube test, swelling test, vanishing interfacial tension test, visual observation during swelling test and vanishing interfacial tension test, and simulation. The proposed method may reduce the uncertainty and avoid doubtful MMP. The method can also demonstrate discrepancies among the results. There were two samples used in this study namely Crude Oil AB-5 and Crude Oil AB-4. It showed that for Crude Oil AB-5 the discrepancies among the results from that of the slim tube test were between $3.9 \%$ and $10.4 \%$ and $0 \%$ and $5.9 \%$ for the temperature of $60{ }^{\circ} \mathrm{C}$ and $66^{\circ} \mathrm{C}$, respectively. The highest discrepancy was shown by the results from the visual observation during vanishing interfacial tension test and the lowest discrepancy was shown by the results from the swelling test. The vanishing interfacial tension test was found to be the fastest method for predicting the MMP. The method also consumed a smaller amount of oil and gas samples for the experiment. The simultaneous method proposed in this study is considered as more proper and exhibits a valuable method for predicting the MMP. This technique has never been found to be performed by previous researchers and accordingly it becomes the strong point of this study to contribute to the global research in the area of MMP determination.
\end{abstract}

\section{Introduction}

The Minimum Miscibility Pressure (MMP) is essential for $\mathrm{CO}_{2}$ injection. The MMP can be determined either by laboratory experiments or numerical studies. Several researchers have introduced experiments methods for predicting the MMP such as Yellig and Metcalfe (1980), Christiansen and Haines (1987), Wang (1986), Hagen and Kossack (1986), Rao (1997), Tsau et al. (2010), Abdurrahman et al. (2015), Alomair et al. (2015), and Rahimi et al. (2017). Some other methods have also been introduced by Cronquist (1978), Johnson and Pollin (1981), Sebastian et al. (1985), Glaso (1985), Ahmed (2000), and Stalkup and Yuan (2005). However, each individual method has distinctive disadvantages in yielding the accurate value as discussed by Danesh (1998), Johns and Orr (1996), Ayirala and Rao (2006), and Tsau et al. (2010). Several researchers have tried simultaneous methods in order to reduce the uncertainties including Thomas et al. (1994), Elsharkawy et al. (1992), Ayirala and Rao (2006), Tsau et al. (2010),

\footnotetext{
* Corresponding author: muslim@eng.uir.ac.id
}

and Abdurrahman et al. (2015). In their study, they compared the results using two or three methods to yield the more reliable MMP. Nevertheless, none of the mentioned researchers have compared the results of using more than three methods.

In this study, we propose a new approach to produce the MMP with high confidence level and less doubtful results. We use various methods including slim tube test, vanishing interfacial tension test, swelling test, visual observation through swelling and vanishing interfacial tests, and simulations in order to obtain the MMP. Our approach is to simultaneously plot results of slim tube test vs. swelling test, VIT test $v s$. swelling test, and slim tube test $v s$. VIT test in the same graph. In the analysis, we include results of visual observation and simulations to obtain more reasonable MMP value.

\section{Preparation and procedures}

Various stages are intentionally prepared to yield appropriate results of either slim tube test, swelling test, vanishing 


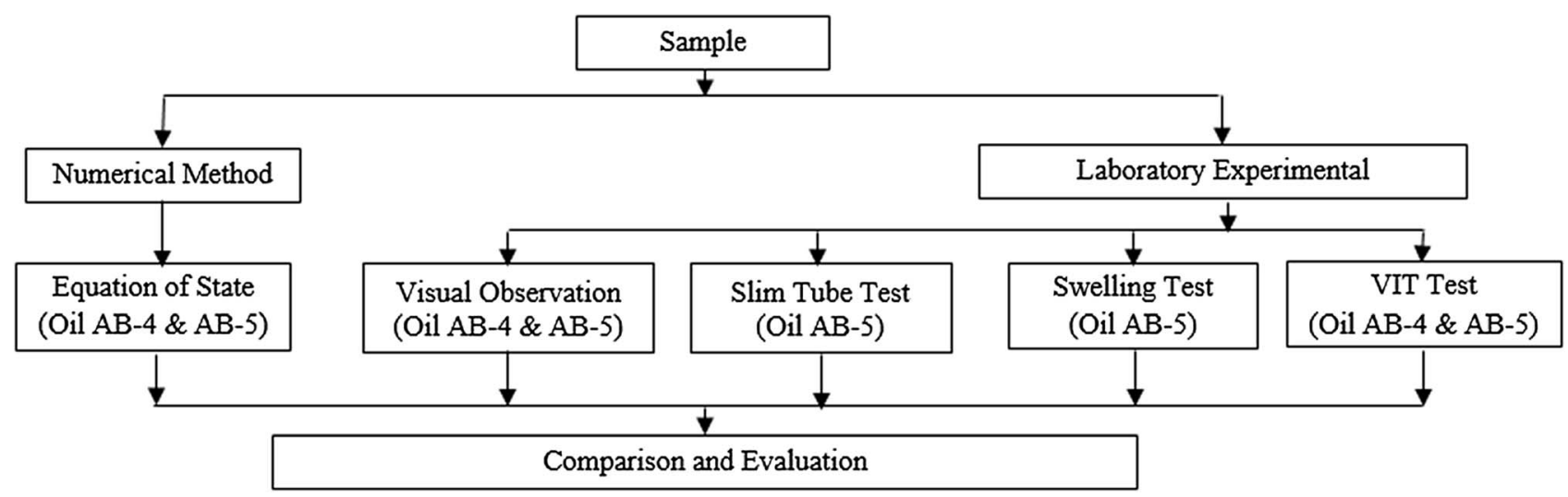

Fig. 1. The procedure of study.

interfacial test, visual observation, and simulation. Afterwards, the entire results are compared to each other as a means to examine any discrepancy among the results. Figure 1 exhibits the flowchart of our research methodology, while the following explanations describe each experiment stage conducted in the current study.

\subsection{Light oil composition and $\mathrm{CO}_{2}$ quality}

Two types of crude oil are used in this study. The crude oil samples are taken from Layer AB-4 and AB-5 within Air Benakat Formation of South Sumatra Basin located in Jambi Province, Indonesia. The composition and other properties of the oil samples are shown in Tables 1 , S1a, and S1b. The $\mathrm{CO}_{2}$ gas used in this study has $99.99 \%$ of purity.

\subsection{Experimental apparatus and procedures}

\subsubsection{Slim tube test}

The procedure for the experiments generally consists of three major stages including preparation, experiment, and cleaning stages. The stages applied for the slim tube test as well as the other tests. The preparation stage for the slim tube test includes leak testing, slim tube saturation using the sample of up to 2.0 PV, Back-Pressure Regulator (BPR) setting at the desired pressure, and air bath temperature system setting at the reservoir condition. The experimental stage involves $\mathrm{CO}_{2}$ injection at the rate of $0.2 \mathrm{cc} / \mathrm{min}$ until it reaches $1.2 \mathrm{PV}$, effluent collection in the measuring cylinder and oil volume measurement. At the same time, the change in oil color is observed in the visual cell for estimating the condition of miscibility then the oil recovery is calculated for each pressure and the results are plotted. The cleaning stage involves oil sample cleaning in the slim tube using toluene and then nitrogen. The miscibility is estimated at the break-over point in the plot of recovery factor vs. pressure as suggested by Yellig and Metcalfe (1980). The experimental diagram of the slim tube test is shown in Figure S1. The description and specification of the slim tube is shown in Table S2.

\subsubsection{Swelling test}

The main apparatus used for the swelling test in the present study consists of a high-pressure cell made of sapphire glass. To fill-up the cell by $\mathrm{CO}_{2}$ we use precision pump namely ISCO Pump 250DM. A heater is used to control the temperature of the air bath system. To help control the $\mathrm{CO}_{2}$ liquid state before it is injected into the cell we use a cooler. To obtain images and to record the course of the experiment we use a simple camera located outside of the air bath system. A stirring bar located inside the cell is used to mix the $\mathrm{CO}_{2}$ and oil until it reaches its equilibrium condition. A rare magnet located within a slot outside the cell is used to control the movement of the bar. Other standard auxiliary equipment for measuring pressure and temperature are also included in the experimental system. Our swelling test experimental diagram is shown in Figure 2.

\subsubsection{Vanishing interfacial test}

The experimental diagram of the vanishing interfacial test is shown in Figure S2. Two syringe pumps from ISCO Company is used for water and $\mathrm{CO}_{2}$ injections and a goniometer apparatus from Rame-Hart Instrument Co. combined with a visual cell is used for this experiment. A high-pressure and high-temperature visual cell is equipped to measure the Interfacial Tension (IFT) in reservoir condition. The cell diameter is $30 \mathrm{~mm}$, its height is $60 \mathrm{~mm}$, and its thickness is $16 \mathrm{~mm}$. The maximum operating pressure and temperature of the visual cell are $3000 \mathrm{psi}$ and $300{ }^{\circ} \mathrm{C}$, respectively. The needle, which has Outside Diameter (OD) of $0.91 \mathrm{~mm}$ and length of $50 \mathrm{~mm}$ and made from stainless steel is used. A pair of face-to-face sapphireglass window is equipped within the visual cell. The glass windows with the thickness of $10 \mathrm{~mm}$ and the diameter of $30 \mathrm{~mm}$ is attached to the visual cell. A certain volume of dead-oil is mounted on the stainless-steel piston-chamber with 0-4000 psi maximum operating pressure. A metering valve and a check valve are applied to ensure the constant oil flow rate and to prevent the flow-back within the cell. The temperature is measured with a calibrated thermocouple located inside the cell. Afterwards, the pressure of the 
Table 1. Sample properties (Abdurrahman et al., 2015).

\begin{tabular}{lcc}
\hline Properties & AB-4 & AB- 5 \\
\hline API Gravity & 20 & 41.38 \\
Reservoir temperature $\left(T_{\mathrm{r}}\right)\left[{ }^{\circ} \mathrm{C}\right]$ & 60 & 65 \\
Reservoir pressure $\left(p_{\mathrm{r}}\right)[\mathrm{psi}]$ & 786 & 1134 \\
Bubble point pressure $\left(p_{\mathrm{b}}\right)[\mathrm{psi}]$ & 740 & 1116 \\
Viscosity $[c \mathrm{p}]$ & 4.6 & 0.21 \\
\hline
\end{tabular}

system is measured through a pressure indicator. All apparatus is connected by using stainless steel tubing lines.

Before initiating the measurement, all lines and the apparatus are cleaned by using toluene, dried by using nitrogen, and vacuumed. The pressure inside the cell is conditioned by injecting some $\mathrm{CO}_{2}$ into the cell. Then, the temperature condition is maintained constant by installing the heater. A sequential experiment is run with a serial condition of pressure that ranges from 700 to $2500 \mathrm{psi}$ and temperature that ranges from $60{ }^{\circ} \mathrm{C}$ to $66^{\circ} \mathrm{C}$. After that, the pressure and temperature inside the cell are constantly maintained according to the desired condition which usually takes about $20-30 \mathrm{~min}$. The water with a specific rate of $0.1 \mathrm{cc} / \mathrm{min}$ is pumped into the chamber and the piston pushes up the dead oil inside the chamber. The dead oil is flown from the chamber through the tubing line until it reaches the needle's tip. When the oil drop reaches the needle's tip, the drop hang and this condition is maintained at stable condition for a certain time by adjusting the metering valve. In this experiment, the stable condition of the drop should be maintained between 40 and $60 \mathrm{~s}$. This time range has been suggested by previous researchers including Yang and Gu (2005) and Yang et al. (2015).

\subsubsection{Visual observation}

\section{Visual observation during swelling test}

Visual observation is performed through images captured as videos or pictures similar to the method conducted previously by Wang (1986). This method has also been performed by Abdurrahman et al. (2015). This method is aimed to observe visually the change in color of the oil as the pressure increases. The observation is done during the extraction-condensation stage when the swelling factor begins to decrease. The MMP should be obtained when the interface of the $\mathrm{CO}_{2}$-rich phase and the $\mathrm{CO}_{2}$ vapor disappears. According to Abdurrahman et al. (2015), this method is obviously not accurate and should be regarded only as an approximate method to estimate the MMP.

\section{Visual observation during VIT test}

Visual observation through videos or pictures during the vanishing interfacial test is used in determining the MMP in this study. This is aimed to observe the change in drop shape of the oil as the pressure increases. When the pressure in the view cell is increased, the $\mathrm{CO}_{2}$ dissolves in the crude oil and the oil drop shape at the tip of the needle gradually changes. This phenomenon occurs until the oil drop disappears at the tip of the needle. The MMP is obtained when the oil and the $\mathrm{CO}_{2}$ become one phase or the oil drop disappears from the needle tip at some higher pressure. This phenomenon can be easily observed by visual means. Again, regardless this method is effective in recognizing when the miscibility occurs; it is obviously not accurate and should be regarded only as approximation.

\subsubsection{Simulation}

Zick (1986) discovered a combination between condensing and vaporizing gas drive mechanisms during miscibility process of $\mathrm{CO}_{2}$ and crude oil. However, this phenomenon cannot be observed using ternary diagram. Therefore, according to Zick, various methods using numerical simulations have been proposed by Jaubert et al. (1998a, 1998b), and Jaubert et al. (2002). Jaubert et al. (1998a) pointed out their study on predicting the MMP using a slim tube simulator. The result showed excellent accuracies compared to 1D simulator. In addition, the compositional slim tube simulator was about 18-80 times faster compared to 1D simulator. Jaubert et al. (1998a) devoted their study on using real petroleum fluid model. They mentioned that one cell simulator has some limitations for estimating the MMP. Due to the time consuming and very expensive experiments for determining the MMP, Jaubert et al. (2002) conducted swelling and multiple contact tests in their study. They concluded that the two tests are faster and cheaper for predicting the MMP.

In these days, numerical simulators offer several options for predicting the MMP. This paper uses CMG simulator of which it provides options in WinProp that can be utilized to calculate the MMP. The Multiple-Contact Miscibility (MCM) option or the First-Contact Miscibility (FCM) pressure for a given oil and solvent at a particular temperature or the Minimum Miscibility Enrichment (MME) level that is required for the multiple- or single-contact miscibility at given temperature, pressure, oil composition, primary and make up gas composition are available in the program. The $\mathrm{C} 7+$ characterization has to be made since the splitting of the oil compositional data of the samples is not possible while the simulator requires components to be defined until C35. The MMP can then be determined for a given solvent composition by entering a range of pressure to be tested. The program reports the MMP if it is found and the mechanism by which the miscibility occurs is achieved. It could be vaporizing or condensing drive mechanisms.

For the MMP calculation in the present study, the pressure increment is divided into 10 steps. The calculation begins with the lowest pressure of 500 psi and terminates at the maximum pressure of $2500 \mathrm{psi}$. The results including the ternary diagrams are collected for each pressure step of which is used to specify the pressure range and values corresponding to the MMP. The required data for the simulation includes temperatures of $60{ }^{\circ} \mathrm{C}$ and $66{ }^{\circ} \mathrm{C}$, pressures ranging from 500 psi to $2500 \mathrm{psi}$, oil composition, and the primary gas composition, i.e. the $\mathrm{CO}_{2}$ with the purity of $99.99 \%$. The equation of state used in this work is Peng-Robinson EOS. The viscosity model is that of Jossi-Stiel-Thodos with the aqueous phase salinity (or $\mathrm{NaCl}$ ) concentration equals to zero. The simulator version is CMG Sofware (2014). 


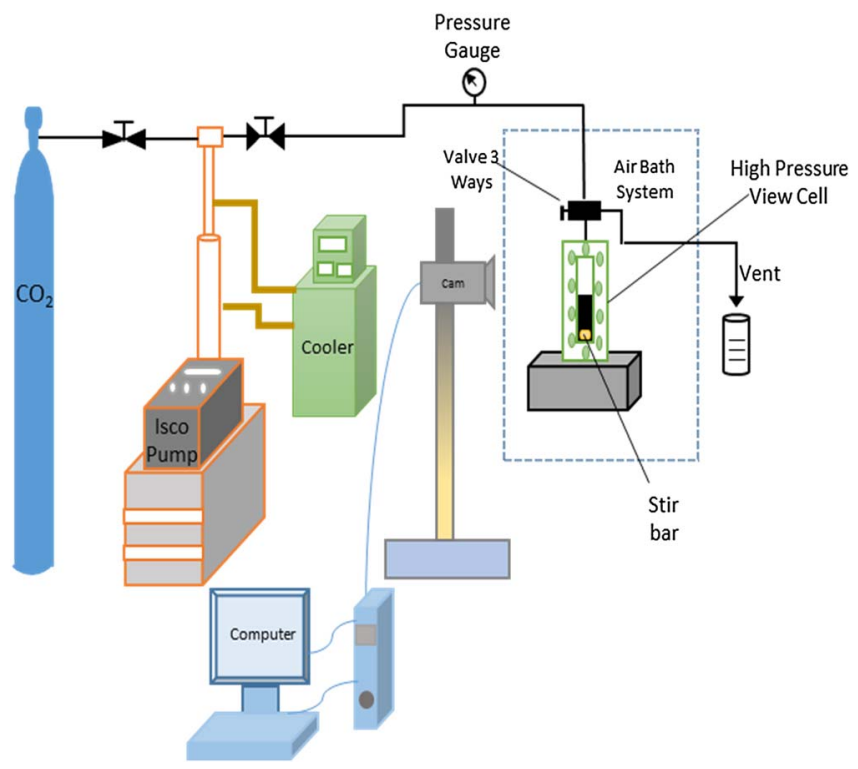

Fig. 2. The diagram of swelling test experiment (Abdurrahman et al., 2015).

\section{Results}

\subsection{Estimating MMP by slim tube test}

The slim tube test experiment uses Crude Oil AB-5 for two reservoir temperature conditions of $60{ }^{\circ} \mathrm{C}$ and $66{ }^{\circ} \mathrm{C}$. The slim tube experiment results for both temperatures are shown in Figure S3. The MMP is determined by using the break-over point technique as suggested by Yellig and Metcalfe (1980). The results from this slim tube experiment show that the miscibility occurs at $1540 \mathrm{psi}$ and $1700 \mathrm{psi}$ for the two temperature conditions of $60{ }^{\circ} \mathrm{C}$ and $66{ }^{\circ} \mathrm{C}$, respectively.

\subsection{Estimating MMP by plots of swelling factor vs. pressure}

The swelling test experiment offers a new technique for estimating the MMP graphically by plotting the resulted swelling factor as a function of pressure. Tsau et al. (2010) suggested in their experiment on how to predict the MMP based on data resulted from a swelling test. The approach involves the determination of the MMP by recognizing the intersection between the extraction-condensation line and the condensation line.

Figure S4 shows that the intersection between the condensation-extraction line and the extraction line that occurs at the pressure of $1600 \mathrm{psi}$ and $1700 \mathrm{psi}$. As a result, for the temperature of $60{ }^{\circ} \mathrm{C}$, the MMP can be estimated as 1600 psi and for the temperature $66{ }^{\circ} \mathrm{C}$, the MMP is obtained as 1700 psi. Due to some technical limitations, this method can only be applied to Crude Oil AB-5.

\subsection{Estimating MMP by plots of IFT vs. pressure}

An experimental study performed by Yang and Gu (2005) explained that during the diffusion process the light and moderate components are rapidly extracted from the oil drop causing the $\mathrm{CO}_{2}$ to be oil-rich. This phenomenon leads to the decrease of the Interfacial Tension (IFT) between the oil and the $\mathrm{CO}_{2}$. However, when the pressure increases and reaches the near-miscibility condition the heavy component remains in the crude oil. At this condition, the oil drop begins to shrink and the IFT reduces quite slowly. Based on this explanation, in the present study two regions are recognized during the vanishing interfacial test. The first is referred to as Region A representing the diffusion stage and the second is referred to as Region B representing the shrinkage stage. In this regard, the MMP is determined by linear extrapolation of the diffusion line versus pressure data to zero value of IFT. A linear regression analysis for estimating the MMP of Crude Oil AB-5 at temperatures of $60{ }^{\circ} \mathrm{C}$ and $66{ }^{\circ} \mathrm{C}$ results in the equations below:

$$
\mathrm{IFT}=-0.0262 \times P+42.22
$$

$$
\mathrm{IFT}=-0.0226 \times P+40.17 .
$$

The first equation is for estimating the MMP at $60{ }^{\circ} \mathrm{C}$ with the correlation coefficient is found to be $R^{2}=99.99 \%$. The second equation is for estimating the MMP at $66{ }^{\circ} \mathrm{C}$ with the correlation coefficient is found to be $R^{2}=99.99 \%$. According to the value of $R^{2}$ for these equations, it is believed that the estimated MMP is considerably acceptable. Nevertheless, these equations can only be applied to a pressure range between $700 \mathrm{psi}$ and $1500 \mathrm{psi}$ for the temperature of $60{ }^{\circ} \mathrm{C}$ and between 700 psi to $1550 \mathrm{psi}$ for the temperature of $66{ }^{\circ} \mathrm{C}$. Above these two-pressure ranges the equation many not be applicable due to the occurrence of different phenomena.

Similarly, a linear regression analysis for estimating the MMP of Crude Oil AB-4 at temperatures of $60^{\circ} \mathrm{C}$ and $66^{\circ} \mathrm{C}$ results in the equations below:

$$
\mathrm{IFT}=-0.0255 \times P+48.92
$$

$$
\mathrm{IFT}=-0.0258 \times P+53.44 .
$$

The first equation is for estimating the MMP at $60{ }^{\circ} \mathrm{C}$ with the correlation coefficient is found to be $R^{2}=98.7 \%$. The second equation is for estimating the MMP at $66{ }^{\circ} \mathrm{C}$ with the correlation coefficient is found to be $R^{2}=99.1 \%$. According to the value of $R^{2}$ for these equations, it is also believed that the estimated MMP is considerably acceptable. Again, because of the occurrence of different phenomena at other pressure values, these equations can only be applied to a pressure range between $700 \mathrm{psi}$ and $1800 \mathrm{psi}$ for the temperature of $60^{\circ} \mathrm{C}$ and 700 and 1900 psi for the temperature of $66{ }^{\circ} \mathrm{C}$.

The MMP estimates under elevated pressure and temperature for Crude Oil AB-5 are shown in Figure S5 while the MMP estimates for Crude Oil AB-4 are shown in Figure S6. Using Equations (1) and (2) at the IFT value equals to zero the interfacial tension shows that the miscibility in Crude Oil AB-5 occurs at 1611 psi and 1777 psi 
for the temperatures of $60{ }^{\circ} \mathrm{C}$ and $66^{\circ} \mathrm{C}$, respectively. It can also be seen that the MMP increases as the temperature increases. Increasing the temperature from $60{ }^{\circ} \mathrm{C}$ to $66{ }^{\circ} \mathrm{C}$ causes the increase in the MMP of about 166 psi or $27.7 \mathrm{psi} /{ }^{\circ} \mathrm{C}$. Similarly, using Equations (3) and (4) at the IFT value equals to zero the interfacial tension shows that the miscibility in Crude Oil AB-4 occurs at 1918 psi and 2072 psi for the temperatures of $60{ }^{\circ} \mathrm{C}$ and $66{ }^{\circ} \mathrm{C}$, respectively. The MMP also increases as the temperature increases. The increase in temperature from $60{ }^{\circ} \mathrm{C}$ to $66^{\circ}$ $\mathrm{C}$ causes the increase in the MMP of about 154 psi or $25.7 \mathrm{psi} /{ }^{\circ} \mathrm{C}$. These results are reasonably consistent with those of Hemmati-Sarapardeh et al. (2013). In their study, the increase of the MMP is about $22.6 \mathrm{psi} /{ }^{\circ} \mathrm{C}$. At higher temperature, the $\mathrm{CO}_{2}$ solubility in the crude oil is lower, which results in a higher MMP.

\subsection{Estimating MMP by visual observations during swelling test and vanishing interfacial test}

\subsubsection{Visual observation during swelling test}

The MMP may be estimated by visual observation during the swelling tests as suggested by Wang (1986). In the present study, the observation is focused on the occurrence when the swelling factor begins to decrease which happens in the extraction-condensation stage. It should be noted here that the MMP estimate through visual observation is certainly subjective and may not reflect the correct MMP. The timing when the extraction-condensation and the extraction stages occur in the cell should also be determined carefully. Relating to the means the MMP is defined, the MMP is estimated when the interface of the $\mathrm{CO}_{2}$-rich phase and the $\mathrm{CO}_{2}$ vapor disappears. Figure S7 and Figure S8 depict the phenomenon during the swelling test for Crude Oil AB-5. The oil color changes slightly as the pressure increases. The more notable oil color change occurs when the swelling factor starts to decrease suggesting that the miscibility of the $\mathrm{CO}_{2}$ and the oil has been achieved. As mentioned by Huang et al. (1989) and Wang (1986), the phenomenon when the oil color starts to change from its original color as the pressure increases is known as the transition zone. While the pressure keeps increasing at this stage, the $\mathrm{CO}_{2}$ and the oil dissolve each other and eventually become one phase. Then, the color of the oil looks brighter. In this experiment, the oil color starts to change at the pressure of $1600 \mathrm{psi}$ and $1700 \mathrm{psi}$ for the temperature of $60{ }^{\circ} \mathrm{C}$ and $66^{\circ} \mathrm{C}$, respectively.

In the extraction process, the pressure is higher than the MMP and the oil color changes to even much brighter as can be seen in Figure S9. This phenomenon results from a large number of moderate components of the oil that has been extracted leaving only the heavier components to remain at the bottom of the cell. The heaviest component subsequently precipitates in the form of black asphaltic flakes as it was also observed by Wang (1986). Assuming the yellow color observed within the cell represents the moderate components, this finding reveals clear evidences that the $\mathrm{CO}_{2}$ extracts only the intermediate components of the oil. Similar observation results were also obtained by previous investigators. In their reports, it was mentioned that the $\mathrm{CO}_{2}$ can extract only the oil components of $\mathrm{C}_{5}$ to $\mathrm{C}_{30}$ (Stalkup, 1984). Photographic sketches illustrating the process of miscibility development were demonstrated by Wang (1986) when the oil shrinks to its minimum volume.

\subsubsection{Visual observation during VIT test}

Wang (1986) suggested that the MMP can be estimated visually during a swelling test experiment. The method has also been done by Abdurrahman et al. (2015) to predict the MMP in their experiments. In the present work, the MMP is also proposed to be predicted by visual observation. Figure S10 depicts the phenomena in Crude Oil AB-5 during vanishing interfacial test at the temperature of $60{ }^{\circ} \mathrm{C}$. Clearly, at 1700 psi, the oil drop shape cannot be recognized as can be seen in the figure. Figure S11 depicts the same phenomena during the vanishing interfacial test for Crude Oil AB-5 at the temperature of $66^{\circ} \mathrm{C}$. The oil drop shape slightly changes as the pressure increases. In this experiment, the oil drop shape starts to change its shape to an irregular form when the pressure is higher than 1650 psi. At the pressure of $1800 \mathrm{psi}$, the oil drop shape cannot be recognized clearly as can be seen in the figure.

Figure S12 depicts the phenomena during the vanishing interfacial test at the temperature of $60{ }^{\circ} \mathrm{C}$ for Crude Oil AB-4. The oil drop slightly changes as the pressure increases. It is clearly seen during the experiment that the oil drop shape does not change to irregular form until the pressure reaches 2600 psi. The IFT between oil and $\mathrm{CO}_{2}$ at this pressure is $0.91 \mathrm{dyne} / \mathrm{cm}$. This value can be categorized as ultra-low IFT. Figure S13 depicts similar phenomena for Crude Oil AB-4 during the vanishing interfacial test at the temperature of $66^{\circ} \mathrm{C}$. It is also clearly seen from the figure that the oil drop shape does not change to any irregular form until the pressure is increased to $2600 \mathrm{psi}$. This is the highest pressure possible during the experiment. Any changes above this pressure is not possible due to some technical reasons. At the pressure of $2600 \mathrm{psi}$, the drop shape is still recognized as regular and the interfacial tension between the oil and $\mathrm{CO}_{2}$ at this pressure is found to be 2.41 dyne $/ \mathrm{cm}$.

\subsection{Determining MMP by simulations}

Our simulation results using Peng-Robinson EOS calculated the MMP for Crude Oil AB-5 as 1670 psi and 1790 psi at $60{ }^{\circ} \mathrm{C}$ and $66{ }^{\circ} \mathrm{C}$, respectively. Similarly, for Crude Oil AB-4, the MMP was found to be $2030 \mathrm{psi}$ and 2240 psi at $60{ }^{\circ} \mathrm{C}$ and $66{ }^{\circ} \mathrm{C}$, respectively. The cell-to-cell method is used in estimating the miscibility by detecting the pressure at which the tie line reaches the critical point. The simulation method is much faster than the experiment. It also does not require much input data. In this work, the MMP calculation is done without any tuning in predicting the phase behavior as suggested by Danesh (1998). The critical properties of the hydrocarbon and non-hydrocarbon components are defined in the simulator as shown in Table S3. The binary interaction coefficients between the hydrocarbon and non-hydrocarbon components are shown in Table S4 and Table S5. 


\section{Discussion}

\subsection{Comparing MMP estimations between slim tube vs. pressure and swelling factor vs. pressure}

In this analysis, the MMP is determined graphically from the results of the swelling test by plotting the swelling factor as a function of pressure. This can only be done for Crude Oil AB-5 because of the limited data from the slim tube test. As suggested by Tsau et al. (2010), the MMP can be obtained when the straight-line curves of the extractioncondensation stage and the extraction stage intersects each other. Therefore, the two curves representing the two stages are important to estimate the occurrence of miscibility and accordingly the MMP cannot be estimated with high-level of certainty if the straight lines cannot be well developed from the experimental data. In the condensation-extraction stage that is also called near-miscibility condition, the lightto-moderate components vaporize quite fast. Meanwhile, due to the already-reduced amount of the components, less moderate components vaporize in the extraction stage. The swelling factor decreases in both stages because $\mathrm{CO}_{2}$ has extracted the light-to-moderate components. The intersection between the extraction-condensation and extraction straight lines is therefore crucial to construct in order to ensure the correct miscibility pressure. The solubility of $\mathrm{CO}_{2}$ in oil increases as the pressure increases during the condensation stage and so the swelling factor. At some point, the oil is rich with the $\mathrm{CO}_{2}$ and at the same time the oil reaches its maximum swelling factor. It is clearly shown in Figure S4 that the swelling factor reaches its maximum value of about 1.3 at 1400 psi. The miscibility, however, has not yet occurred. After the oil is fully saturated by $\mathrm{CO}_{2}$, the extraction-condensation stage begins and few moderate components of the oil move into the $\mathrm{CO}_{2}$ phase as indicated by the decrease in swelling factor. The extraction stage occurs as the pressure increases further where the $\mathrm{CO}_{2}$ vaporizes and more moderate components leave the oil phase causing the swelling factor to decrease continuously but at different rate. As a result, for the temperature of $60{ }^{\circ} \mathrm{C}$, the MMP is determined as 1600 psi (see Fig. S4). Using the same procedure, the results for the other temperature of $66^{\circ} \mathrm{C}$ is also shown in Figure S4. The MMP for this case is obtained as 1700 psi. One thing that is important to note here is the effect of $\mathrm{CO}_{2}$ solubility on the swelling factor. At higher pressure, the $\mathrm{CO}_{2}$ solubility is also higher making its effect on the swelling factor is more significant. Therefore, the swelling factor of 1.4 at $66^{\circ} \mathrm{C}$ and $1600 \mathrm{psi}$ that is higher than that of 1.3 at $60^{\circ} \mathrm{C}$ and $1400 \mathrm{psi}$ in these experiments is mainly due to the effect of pressure which is more dominant than temperature.

It is clearly understood from Figure S4 that the MMP cannot be determined if the extraction stage does not occur so that the intersection between the straight-lines of the extraction-condensation stage and the extraction stage cannot be identified. Because the extraction stage is quite faster than the rate of swelling after the miscibility occurs, the extraction causes the swelling factor to decrease rapidly. This phenomenon was also reported by previous investigators such as Tsau et al. (2010) and Harmon and Grigg (1988).
Regardless the dominant effect of pressure, the temperature in fact plays an important role in the extractioncondensation stage as well as in the extraction stage that follows. Because the solubility of $\mathrm{CO}_{2}$ in oil is low at higher temperatures, the extraction of the oil components is also low. Thus, during the $\mathrm{CO}_{2}$ injection process at the higher temperature of $66{ }^{\circ} \mathrm{C}$, the $\mathrm{CO}_{2}$ dissolves only slightly in the oil as indicated in Figure $\mathrm{S} 4$ causing low concentration of the hydrocarbon that can be extracted. As a result, the oil shrinkage is also low during the extraction-condensation stage and the oil volume returns to its initial condition as indicated by the swelling factor of unity. When the injection is conducted at the lower temperature of $60{ }^{\circ} \mathrm{C}$, a different phenomenon occurs where more $\mathrm{CO}_{2}$ dissolves into the oil and the oil shrinkage is quite high as indicated in Figure S4. Then, because more oil components are extracted during the extraction-condensation stage, the swelling factor decreases to a value of less than 1.0. However, when the temperature increases, the MMP also increases. In the present study, the increase in temperature of $6{ }^{\circ} \mathrm{C}$ leads to the increase of the MMP by $100 \mathrm{psi}$ or about $16.7 \mathrm{psi} /{ }^{\circ} \mathrm{C}$. This result is very much close to the result of the work by Elsharkawy et al. (1992). They reported that the increase of the MMP affected by the increase of temperature fell within the range of $18.10 \mathrm{psi} /{ }^{\circ} \mathrm{C}$ and $27.02 \mathrm{psi} /{ }^{\circ} \mathrm{C}$. Figure $\mathrm{S} 4$ clearly shows this effect of temperature on the MMP. At higher temperatures, the condensation-extraction and the extraction lines will be slightly flatter than the lines at lower temperatures. The logical reasoning for this phenomenon may be because at higher temperature the $\mathrm{CO}_{2}$ extract less oil components and accordingly it requires higher pressure to achieve miscibility condition resulting in higher MMP.

Figure S14 displays combined plots comparing the results of the slim tube experiment and those of the swelling test each of which for the temperatures of $60^{\circ} \mathrm{C}$ and $66^{\circ} \mathrm{C}$. Analyzing the plots graphically, the MMP resulted from the swelling test is obviously in good agreement with that from the slim tube experiment. In other words, the MMP obtained from the swelling test in the present study is considerably correct. This result therefore invalidates the doubting relationship previously noted by Harmon and Grigg (1988) between the MMP obtained from the slim tube experiment and that from the swelling test. The difference between the MMP obtained from the slim tube and that from the swelling test is about $3.9 \%$ for the temperature of $60{ }^{\circ} \mathrm{C}$ and basically zero for the temperature of $66^{\circ} \mathrm{C}$ (see Table S6).

\subsection{Comparing MMP estimations between swelling factor vs. vanishing interfacial test}

In this analysis, the results for Crude Oil AB-5 are examined. Figure S15 shows combined plots comparing the results of the vanishing interfacial test and that of the swelling test at the temperatures of $60{ }^{\circ} \mathrm{C}$ and $66{ }^{\circ} \mathrm{C}$, respectively. A graphical analysis on the plots clearly shown that the MMP resulted from the swelling test is also in good agreement with that of the vanishing interfacial test. As a result, the MMP obtained from the swelling test and that from the vanishing interfacial test in the present study 
proved to be considerably correct. As displayed in Table S7, the differences between the results of the swelling test and that of the vanishing interfacial test are about $0.7 \%$ and $4.3 \%$ for the temperature of $60{ }^{\circ} \mathrm{C}$ and $66^{\circ} \mathrm{C}$, respectively. It follows that the MMP obtained from the swelling test and that from the vanishing interfacial test at low temperatures are closer to each other than the same results at higher temperatures. In the meantime, the MMP obtained from vanishing interfacial test is slightly higher than that obtained from the swelling test. However, the difference is still reasonable as it is considerably a small figure.

Following the explanation provided by Yang and $\mathrm{Gu}$ (2005), two regions namely Region A for diffusion stage and Region $\mathrm{B}$ for shrinkage stage are recognized. In Region A the $\mathrm{CO}_{2}$ diffuses into the crude oil causing the oil to swell and accordingly the Interfacial Tension (IFT) to decrease. In this study, the IFT in Region A is found to decrease from 24.5 dyne $/ \mathrm{cm}$ to 2.93 dyne $/ \mathrm{cm}$ at $60{ }^{\circ} \mathrm{C}$ and 24.9 dyne $/ \mathrm{cm}$ to 3.4 dyne $/ \mathrm{cm}$ at $66{ }^{\circ} \mathrm{C}$. However, as the pressure continues to increase the oil drop is lacking of moderate component leaving heavy component as the main constituent of the oil drop. In that condition the oil volume decreases owing to the shrinkage of the oil drop. On the other hand, in Region B the remaining heavy component in the oil drop only causes the IFT to slowly decrease. In this region, the IFT decreases from 2.6 dyne $/ \mathrm{cm}$ to 2.5 dyne $/ \mathrm{cm}$ at $60{ }^{\circ} \mathrm{C}$ and 3.0 dyne $/ \mathrm{cm}$ to 2.1 dyne $/ \mathrm{cm}$ at $66{ }^{\circ} \mathrm{C}$. This phenomenon is clearly shown in Figure S15. Regarding the MMP explanations according to the molecular effects, the logical reasoning may be expressed as follows. When the $\mathrm{CO}_{2}$ injection pressure increases at Region $\mathrm{A}$, more $\mathrm{CO}_{2}$ molecules will diffuse into the oil. Thus, the oil density decreases rapidly. The higher the injection pressure, the denser the $\mathrm{CO}_{2}$ causing its density to be higher. This condition minimizes the density difference between the $\mathrm{CO}_{2}$ and the oil drop. Lower density difference means the operating intermolecular forces between the $\mathrm{CO}_{2}$ and the oil will be close at Region $\mathrm{B}$. The interface between the $\mathrm{CO}_{2}$ and the oil disappears when the operating intermolecular force between the two phases is in balanced condition. It is also believed that near-miscibility occurs at the intersecting point between Region A and B lines in the plot of the IFT vs. pressure. Prior to the near-miscibility region the IFT decreases more rapidly as the pressure increases. In contrast, after the near-miscibility region (or shrinkage region) the IFT continues but slowly decreases as the pressure increases. This is probably because of the domination of the heavy component.

It follows from the above that the existence of the intersecting lines of the extraction-condensation and the extraction stages is crucial in estimating the MMP through swelling test. During the swelling test, three regions namely condensation, condensation-extraction, and extraction occur and can be recognized easily. These regions do not exist and cannot be recognized during the vanishing interfacial test. The logical reasoning may be expressed as follows. When the swelling test is conducted, the oil volume is as much as $2.1 \mathrm{~mL}$ and it causes more $\mathrm{CO}_{2}$ to dissolve into the oil. In that process, it is easy to recognize the three regions through the view cell. However, when a vanishing interfacial test is conducted the oil surrounded by the $\mathrm{CO}_{2}$ is too small averaging only $3-8 \mu \mathrm{L}$. Because of the small oil volume, the process is not able to depict the three regions such as the process occurs during swelling test. However, from the similarity of the curve trend and the slope changes between the swelling test and the vanishing interfacial test during the extraction process it is believed that at the pressure above the MMP the heavy component is dominating the oil composition. Figure S4 as well as Figure S5 to Figure S6 may be useful to describe such phenomenon.

It is unfortunate that due to some technical reasons the swelling test and the slim tube test cannot be performed for Crude Oil AB-4. Therefore, the similar analysis to the results for Crude Oil AB-5 cannot be done for Crude Oil AB-4. However, as the composition may affect considerably the MMP as explained above, the higher molecular weight of the heptane-plus in Crude Oil AB-4 compared to Crude Oil AB-5 may be responsible for the higher MMP of Crude Oil AB-4 in the IFT experiment at both temperatures of $60{ }^{\circ} \mathrm{C}$ and $66{ }^{\circ} \mathrm{C}$. To be precise, different composition between the two oil samples results in different MMP. In this case, the higher content of heavy component in Crude Oil AB-4 results in the higher MMP. Line B or shrinkage line of the IFT results proves the heavy component richness of Crude Oil AB-4. Also, the IFT still exist even at high pressures. Hence, the MMP in Crude Oil AB-4 is logically higher than that of Crude Oil AB-5. Table S8 shows the comparison of the MMP for the two oil samples based on the VIT test results.

\subsection{Comparing MMP estimations by slim tube vs. VIT test}

Because of the slim tube and VIT tests results availability, further analysis can be done for Crude Oil AB-5. Figure S16 shows combine plots comparing the results of the slim tube and VIT tests at $60{ }^{\circ} \mathrm{C}$ and $66{ }^{\circ} \mathrm{C}$, respectively. The MMP resulted from the VIT test is in good agreement with that obtained from the slim tube test. It then follows that the MMP obtained from the VIT test is considered satisfactorily correct. By plotting the slim tube and the VIT tests results in the same graph, the uncertain and doubtful MMP from the VIT result can be diminished. The plot also provides enhancement to the MMP estimation. Table S9 shows the results of the MMP as well as their differences between the two tests. As shown in the table, the discrepancies between the two methods are $4.5 \%$ at $66{ }^{\circ} \mathrm{C}$ and $4.6 \%$ at $66^{\circ} \mathrm{C}$, respectively. In other words, the effect of temperature is not significant.

\subsection{Comparing MMP estimations by experiments vs. simulation}

The slight disagreement between the results of experimental and simulation methods is most likely caused by the specific property of the oil sample used in each method. The slim tube test, the vanishing interfacial test and the swelling test use dead oil samples while the simulation uses live oil samples. The gas composition in the live oil sample such as methane and nitrogen causes the MMP slightly higher 
(Dong et al., 2000). Table S10 shows the differences between the results of the swelling test and the simulation for Crude Oil AB-5 are about $4.2 \%$ and $5.0 \%$ at the temperature of $60{ }^{\circ} \mathrm{C}$ and $66^{\circ} \mathrm{C}$, respectively. Meanwhile, the differences between the results of the vanishing interfacial test and that of the simulation are about $3.5 \%$ and $0.7 \%$ at the temperature of $60{ }^{\circ} \mathrm{C}$ and $66^{\circ} \mathrm{C}$, respectively. Then, the differences between the results of the slim tube test and that of simulation are about $7.8 \%$ and $5.0 \%$ at the temperature of $60{ }^{\circ} \mathrm{C}$ and $66{ }^{\circ} \mathrm{C}$, respectively. It then follows that all the experimental methods including the swelling test, the vanishing interfacial test, and the slim tube test provide satisfactory estimates of the MMP. It can also be seen in the table that the MMP estimated by the VIT method has the closest value to the MMP from the EOS method. In contrast, the highest difference from EOS method is the result of the slim tube test. Furthermore, the difference of the MMP values obtained from swelling test to that of the EOS is consistent at both temperatures. As a conclusion, the MMP at a specific temperature resulted from the methods used in the present study does not show a single or exactly the same value. There is always a discrepancy among the results no matter how small it is.

Generally, the MMP data obtained from the use of EOS is higher than those obtain from experimental methods including the VIT test, the swelling test, and the slim tube test particularly for Crude Oil AB-4. Shown in Table S11, the difference between the results of the vanishing interfacial test and the simulation is about $5.5 \%$ at the temperature of $60{ }^{\circ} \mathrm{C}$ and $7.5 \%$ at $66{ }^{\circ} \mathrm{C}$. Clearly the difference of the MMP using EOS is higher for Crude Oil AB-4 than that of Crude Oil AB-5. It may provide further information and possible analysis if there are some data obtained from slim tube and swelling tests for Crude Oil AB-4. Accordingly, there may some other conclusions that can be drawn.

\section{Conclusion}

Drawing from the results of the present study, the following are summarized conclusions.

1. Very few investigators used simultaneous methods in predicting the MMP.

2. Analysis using data plotting from simultaneous methods has never been examined in detail previously.

3. The use of simultaneous methods is able to reduce uncertainties and doubts of the resulted MMP.

4. The MMP obtained from the slim tube test has been used as the standard result or baseline in the present study.

5. The visual observation either during the swelling test or interfacial tension test is worthy for recognizing the timing of the miscibility to occur during experiments.

6. The interfacial tension test is the most effective method in utilizing oil samples and gas for the experiment. Less time consumption and small amount of oil and gas to utilize are the main advantages of using this method regardless the analysis that shows slightly higher discrepancies than that of the slim tube test.
7. Despite the closeness of the results, each method has shown results that are in fact different to each other. However, in general, all the methods can be properly used for predicting the MMP.

Acknowledgments. This work is financially supported by the Energy Resources R\&D Program of the Korea Institute of Energy Technology Evaluation and Planning (KETEP) and by the Korean Government Ministry of Trade, Industry and Energy through Sejong University, Korea. The Authors also wish to thank Universitas Islam Riau and $C M G$ for the encouragement of writing this paper.

\section{Supplementary Material}

Supplementary material is available at https://ogst.ifpenergiesnouvelles.fr/10.2516/ogst/2019028/olm.

Figures S1 to S16 and Tables S1 to S11.

\section{References}

Abdurrahman M., Permadi A.K., Bae W.S. (2015) An improved method for estimating minimum miscibility pressure through condensation - extraction process under swelling tests, J. Pet. Sci. Eng. 131, 165-171. https://doi.org/10.1016/j.petrol. 2015.04.033.

Ahmed T. (2000) Minimum Miscibility Pressure from EOS, Petroleum Society of Canada - Canadian International Petroleum Conference, 4-8 June, Calgary, Alberta. https://doi.org/10.2118/2000-001.

Alomair O., Malallah A., Elsharkawy A., Iqbal M. (2015) Predicting $\mathrm{CO}_{2}$ Minimum Miscibility Pressure (MMP) using Alternating Conditional Expectation (ACE) algorithm, Oil Gas Sci. Technol. - Rev. IFP Energies nouvelles 70, 6, 967982. https://doi.org/10.2516/ogst/2012097.

Ayirala S.C., Rao D.N. (2006) Comparative Evaluation of a New MMP Determination Technique, Society of Petroleum Engineers - SPE/DOE Symposium on Improved Oil Recovery, 22-26 April, Tulsa, Oklahoma, USA. https://doi.org/ 10.2118/99606-MS.

Christiansen R.L., Haines H.K. (1987) Rapid measurement of minimum miscibility pressure with the rising-bubble apparatus, Soc. Pet. Eng. - SPE Reserv. Eng. 2, 4, 523-527. https://doi.org/10.2118/13114-PA.

CMG Software (2014) WinProp User's Guide, Computer Modelling Group, Calgary, Alberta, Canada.

Cronquist C. (1978) Carbon dioxide dynamic miscibility with light reservoir oils, US Doe Annual Symposium, Tulsa.

Danesh A. (1998) PVT and phase behaviour of petroleum reservoir fluids.

Dong M., Huang S., Srivastava R. (2000) Effect of solution gas in oil on $\mathrm{CO}_{2}$ minimum miscibility pressure, J. Can. Pet. Technol. 39, 11. https://doi.org/10.2118/00-11-05.

Elsharkawy A.M., Poettmann F.H., Christiansen R.L. (1992) Measuring minimum miscibility pressure: slim-tube or risingbubble method? Soc. Pet. Eng. https://doi.org/10.2118/ 24114-MS.

Glaso O. (1985) Generalized minimum miscibility pressure correlation, Soc. Pet. Eng. 25, 6. https://doi.org/10.2118/ 12893-PA. 
Hagen S., Kossack C.A. (1986) Determination of minimum miscibility pressure using a high-pressure visual sapphire cell, Society of Petroleum Engineers - SPE Enhanced Oil Recovery Symposium, 20-23 April, Tulsa, Oklahoma. https://doi.org/ 10.2118/14927-MS.

Harmon R.A., Grigg R.B. (1988) Vapor-density measurement for estimating minimum miscibility pressure, Society of Petroleum Engineers - SPE Reservoir Engineering, 3, 4. https://doi.org/10.2118/15403-PA.

Hemmati-Sarapardeh A., Ayatollahi S., Ghazanfari M.-H., Masihi M. (2013) Experimental determination of interfacial tension and miscibility of the $\mathrm{CO}_{2}$ - crude oil system; temperature, pressure, and composition effects, J. Chem. Eng. Data 61-69. https://doi.org/10.1021/je400811h.

Huang S.S., de Wit P., Jha K.N. (1989) A laboratory miscible displacement study for the recovery of Saskatchewan's crude oilPetroleum Society of Canada - Petroleum Conference of The South Saskatchewan Section, 25-27 September, Regina. https://doi.org/10.2118/SS-89-03.

Jaubert J.-N., Arras L., Neau E., Avaullee L. (1998a) Properly defining the classical vaporizing and condensing mechanisms when a gas is injected into a crude oil, Ind. Eng. Chem. Res 37, 1, 4860-4869. https://doi.org/10.1021/ie9803016.

Jaubert J.-N., Wolff L., Neau E., Avaullee L. (1998b) A very simple multiple mixing cell calculation to compute the minimum miscibility pressure whatever the displacement mechanism, Ind. Eng. Chem. Res 37, 4854-4859, https://doi.org/10.1021/ie980348r.

Jaubert J.N., Avaullee L., Pierre C. (2002) Is it still necessary to measure the minimum miscibility pressure? Ind. Eng. Chem. Res. 41, 303-310. https://doi.org/10.1021/ie010485f.

Johns R.T., Orr F.M. Jr (1996) Miscible Gas Displacement of Multicomponent Oils, SPE J. 1, 1, https://doi.org/10.2118/ 30798-PA.

Johnson J.P., Pollin J.S. (1981) Measurement and correlation of $\mathrm{CO}_{2}$ miscibility pressures, Society of Petroleum Engineers. https://doi.org/10.2118/9790-MS.

Rahimi V., Bidarigh M., Bahrami P. (2017) Experimental study and performance investigation of miscible water-alternating$\mathrm{CO}_{2}$ flooding for enhancing oil recovery in the Sarvak formation, Oil Gas Sci. Technol. - Rev. IFP Energies nouvelles 72, 6, 35, https://doi.org/10.2516/ogst/2017030.
Rao D.N. (1997) A new technique of vanishing interfacial tension for miscibility determination, J. Fluid Phase Equilibria 139, 1-2, 311-324. https://doi.org/10.1016/S0378-3812(97) 00180-5.

Sebastian H.M., Wenger R.S., Renner T.A. (1985) Correlation of minimum miscibility pressure for impure $\mathrm{CO}_{2}$ streams, J. Pet. Technol. 37, 11, https://doi.org/10.2118/12648-PA.

Stalkup F.I. (1984) Miscible Displacement (SPE Monograph Series), Society of Petroleum Engineers of AIME, Dallas New York.

Stalkup F., Yuan H. (2005) Effect of EOS characterization on predicted miscibility pressure, Society of Petroleum Engineers - SPE Annual Technical Conference and Exhibition, 9-12 October, Dallas, Texas.

Thomas F.B., Zhou X.L., Bennion D.B., Bennion D.W. (1994) A comparative study of RBA, P-x, multicontact and slim tube results, J.Can. Pet. Technol. 33, 2, https://doi.org/10.2118/ 94-02-02.

Tsau J.S., Bui L.H., Willhite G.P. (2010) Swelling/extraction test of a small sample size for phase behavior studySociety of Petroleum Engineers - SPE Improved Oil Recovery Symposium, 24-28 April, Tulsa, Oklahoma, USA. https://doi.org/ 10.2118/129728-MS.

Wang G.C. (1986) A study of crude oil composition during $\mathrm{CO}_{2}$ extraction process, Society of Petroleum Engineers. https://doi.org/10.2118/15085-MS.

Yang D., Gu Y. (2005) Interfacial interactions between crude oil and $\mathrm{CO}_{2}$ under reservoir conditions, Pet. Sci. Technol. (November 2014), 37-41, https://doi.org/10.1081/LFT200035536

Yang Z., Liu X., Hua Z., Ling Y., Li M., Lin M., Dong Z. (2015) Interfacial tension of $\mathrm{CO}_{2}$ and crude oils under high pressure and temperature, Colloids Surf. A Physicochem. Eng. Aspects 482, 611-616. https://doi.org/10.1016/j.colsurfa.2015.05.058.

Yellig W.F., Metcalfe R.S. (1980) Determination and prediction of $\mathrm{CO}_{2}$ minimum miscibility pressures, J. Pet. Technol. 32, 1, https://doi.org/10.2118/7477-PA.

Zick A.A. (1986) A combined condensing/vaporizing mechanism displacement of oil by enriched gases, Society of Petroleum Engineers - SPE Annual Technical Conference and Exhibition, 5-8 October, New Orleans, Louisiana. https://doi.org/ 10.2118/15493-MS. 